\title{
Gender moderates the relationship between childhood abuse and internalizing and substance use disorders later in life: a cross-sectional analysis
}

Xiangfei Meng ${ }^{1 *}$ and Carl D'Arcy ${ }^{2}$

\begin{abstract}
Background: Although some studies examined the moderating role of gender in the relationship between childhood maltreatment and mental disorders later in life, a number of them examined the effects of only one or two types of maltreatment on an individual mental disorder, for instance, depression, substance use. It is of considerable clinical and theoretical importance to have in-depth understanding what roles of different types of childhood abuse play out in a wide range of mental disorders among women and men using well accepted instruments measuring abuse and mental disorders. The present study aimed to examine this issue using a large nationally representative population sample to explore the gender effect of different types of childhood abuse in mental disorders, and assess the moderating role of gender in the abuse-mental disorder relationship.
\end{abstract}

Methods: Using data from the Canadian Community Health Survey 2012: Mental Health we sought to answer this question. Respondents with information on childhood maltreatment prior to age 16 were selected $(N=23,395)$.

Results: We found: i) strong associations between childhood abuse frequency and gender; ii) significant differences between men and women in terms of mental disorders; iii) strong associations between childhood abuse and mental disorders; and, iv) gender moderated the role of childhood abuse history on adulthood mental disorders. Females with a history of sexual abuse and/or exposure to interpersonal violence were at a greater risk of alcohol abuse or dependence later in life.

Conclusions: Intervention should occur as early as possible, and should help female victims of childhood sexual abuse and/or exposure to interpersonal violence, and their families to build more constructive ways to effectively reduce the negative affects of these experiences. Recognition of the moderating role of gender on the relationship between childhood abuse history and mental disorders later in life may aid clinicians and researchers in providing optimal health services.

Keywords: Childhood maltreatment, Internalizing, Substance use, Interaction, Gender

\section{Background}

Childhood maltreatment, or abuse, is a major public health and social welfare problem. It includes psychological abuse, physical abuse, sexual abuse and neglect [1]. It can cause death, disability, and long-term consequences that result in actual or potential harm to a child's health, development into adulthood and their dignity. A WHO

\footnotetext{
* Correspondence: xiangfei.meng@mcgill.ca

${ }^{1}$ Department of Psychiatry, McGill University and Douglas Mental Health

University Institute, 6875 boul. LaSalle, Verdun, Montreal, QC, Canada

Full list of author information is available at the end of the article
}

2006 report on children maltreatment stressed the need to draw public attention to its health and behavioural impact and that investment in resources is required to both monitor and prevent its occurrence [2].

It is estimated that every year worldwide about $4-16 \%$ of children are physically abused, $10 \%$ are neglected or psychologically abused, 5 to $10 \%$ of girls and up to $5 \%$ of boys are subject to penetrative sexual abuse [3]. Childhood maltreatment significantly contributes to child mortality, morbidity, and other lasting effects on physical and mental 
health, school performance, alcohol and illegal drug misuse, and criminal behaviour [4].

Studies on childhood maltreatment have identified that: childhood maltreatment is prevalent and has a significant consequence on psychological and health outcomes [1, 3, 5]; several parental and child factors are associated with high risk of being maltreated [6, 7]; boys are more likely to have experienced physical abuse, but girls tend to have more negative consequences of physical abuse, and were more likely to be sexually abused $[8,9]$; and, effective prevention programs are recommended to prevent the occurrence of maltreatment [10,11]. Adverse childhood experiences are associated with enduring changes to the child's nervous, endocrine and immune systems [12].

Epidemiological studies have consistently found the gender differences in many mental disorders, for example, women are more likely to suffer mood and anxiety disorders $[13,14]$, but they report lower rates of substance abuse than men [15]. Large-scale epidemiological studies have consistent identified gender differences in the prevalence of internalizing and substance use disorders in the general population, with females suffering an increased risk of internalizing disorders and males of externalizing disorders $[16,17]$. A cross-national study of countries in Africa, the Americas, Europe, the Middle East, and the Pacific also found women had more internalizing disorders, whereas men had more externalizing disorders - alcohol and drug substance use [18]. Recently, Steel et al. [19] in their systematic review synthesized the evidence over 174 surveys across 63 countries found that women were more likely to experience mood and anxiety disorders, whereas men were more likely to have substance use disorders.

Although some studies examined the moderating role of gender in the relationship between childhood maltreatment and adult mental disorders, a number of them examined only one or two types of maltreatment on an individual mental disorder, for instance, depression, substance use, etc. [20,21]. Findings on the moderating role of gender in the abuse-mental disorder relationship are inconsistent across studies. One explanation of this inconsistency is the application of different psychometric properties of abuse measures and diagnostic instruments of mental disorders [21]. Furthermore, Kristman-Valente \& Well [22] in their systematic review of longitudinal studies analyzed the role of gender in the association between childhood maltreatment and substance use and because of differences in measurement, sample composition, and developmental timing of substance use, concluded that the moderating effect of gender remained unclear, as very few studies had been conducted to explore the role of gender in this relationship.

It is of considerable clinical and theoretical importance to have in-depth understanding what roles of different types of childhood abuse play out in a wide range of mental disorders among women and men using well accepted instruments measuring abuse and mental disorders. The present study aimed to meet this need by using a large nationally representative population sample to explore the gender effect of childhood abuse in mental disorders, and assess the moderating role of gender in the childhood abuse-mental disorder relationship.

\section{Methods}

\section{Data source}

Data was from the master file of the Canadian Community Health Survey 2012: Mental Health (CCHS 2012-MH). Permission was granted for analyzing this master file of the CCHS 2012-MH from Statistics Canada. This survey is a cross-sectional study that collected information about lifetime and 12-month mental health status, access to and perceived need for formal and informal services and supports, functioning and disability, and factors determining health status. The survey used a multistage stratified cluster sampling design to recruit a representative sample of respondents aged 15 and over residing in the 10 provinces of Canada (not including those residents living in the three territories, indigenous communities, and institutions, and full-time members of the Canadian Armed Forces). The overall response rate was $79.8 \%$, resulting in a total sample size of 25,113 respondents. The Canadian Community Health Survey 2012: Mental Health was approved by the Statistics Canada ethics review committee. It was an interview survey using computer assisted personal interviewing technology. Respondents were informed and gave written consent to being surveyed. Only respondents aged 18 years and over were asked to answer questions about childhood abuse that occurred before the age of 16 years $(N=23,395)$ and thus included in this study.

\section{Dependent variables- mental disorders}

The survey used the structured Composite International Diagnostic Interview, which is based on the criteria of the Diagnostic and Statistical Manual of Mental disorders, $4^{\text {th }}$ edition, to assess the lifetime and 12-month diagnoses of mental disorders. Disorders assessed included major depression, hypomania, mania, bipolar disorder, generalized anxiety disorder, alcohol abuse or dependence, and drug abuse or dependence. Respondents with major depression, bipolar disorder, generalized anxiety disorder, hypomania, mania, or mood disorder, were further classified as having internalizing disorders. Those with alcohol abuse or dependence or drug abuse or dependence were classified as having externalizing disorders.

\section{Independent variables}

Childhood maltreatment, including physical abuse, sexual abuse, and exposure to interpersonal violence ('parent hit other adult'), was assessed in the survey using the questions from an abbreviated version of the Childhood Experiences 
of Violence Questionnaire [23]. To facilitate the respondent's comfort and privacy, the administration of this module relied on a companion response booklet, which showed both the question and the response categories, so that neither needed to be read aloud. The five categories representing frequency of childhood abuse occurrence were: never, 1-2 times, 3-5 times, 6-10 times, or $>10$ times.

\section{Covariates}

Socio-demographic variables including age, gender, education, income, marital status, place of residence, immigrant status were considered as covariates in the analyses.

\section{Statistical analyses}

The bootstrapping method recommended by Statistics Canada was used to account for the complex sampling design and make sure the results could be generalized to the general population in Canada. We calculated the overall and gender-specific proportions of all different types of childhood abuse and the gender-specific prevalence for selected mental disorders. The prevalence of selected mental disorders by childhood abuse was estimated. We also determined the distribution of socio-demographic variables by different types of childhood abuse experience and tested the interaction between gender and different types of childhood abuse for selected mental disorders using multivariate logistic regression analyses.

\section{Results}

Childhood abuse frequency by gender

Table 1 shows that there were significantly statistical differences between men and women for all different types of

Table 1 Proportions of childhood abuse frequency by gender

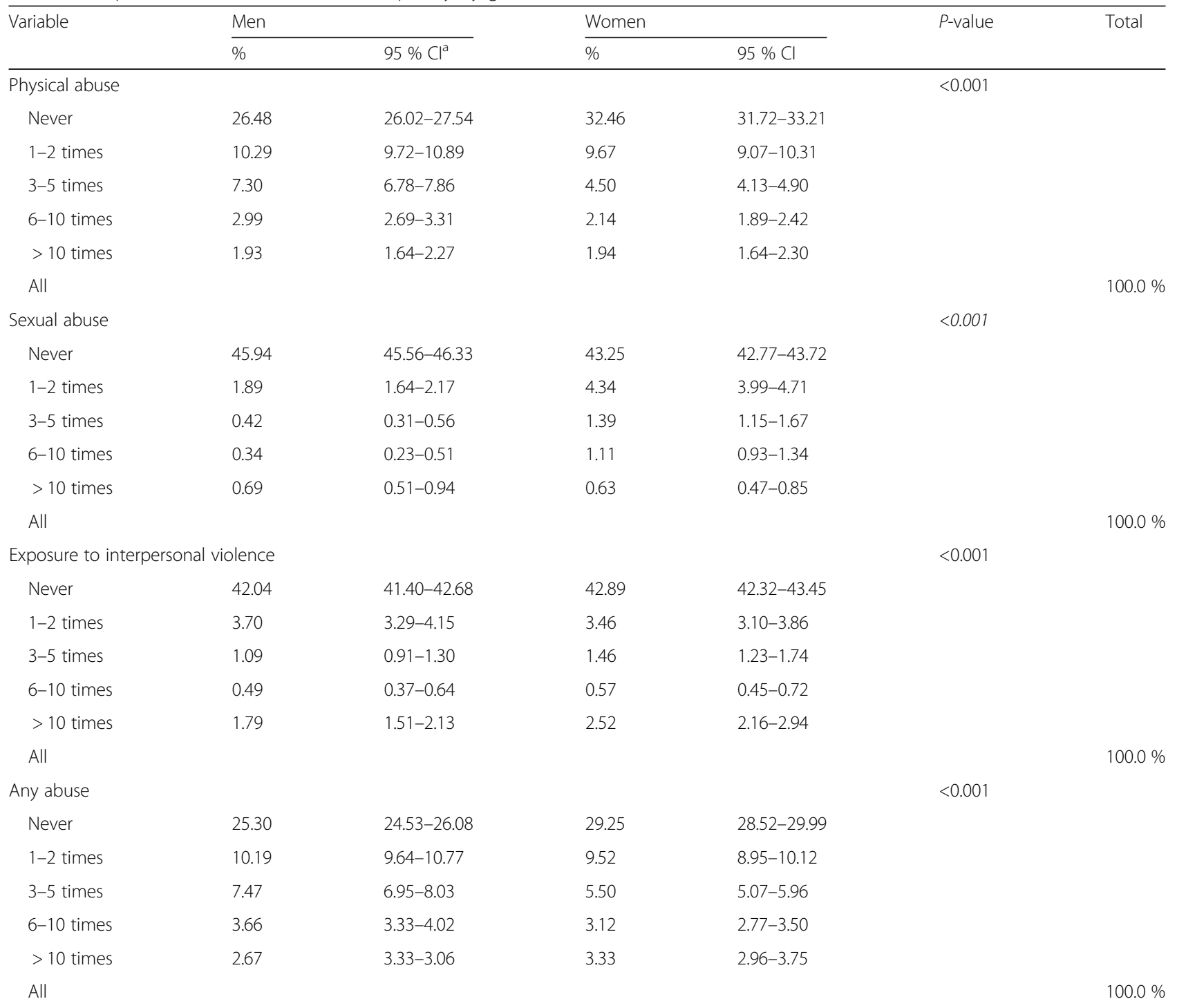


childhood abuse frequencies $(p<0.001)$, including physical abuse, sexual abuse, exposure to interpersonal violence, and any abuse. Men were more likely exposed to frequent physical abuse, interpersonal violence, and any abuse, whereas women reported more frequent sexual abuse.

\section{Socio-demographic variables by different types of childhood abuse}

Table 2 reports the distribution of socio-demographic variables among respondents with and without a history of childhood abuse. Respondents aged 45 to 64 years had the highest rates of all kinds of childhood abuse compared to those in other age groups. Females were more likely to report sexual abuse and exposure to interpersonal violence, whereas males more likely to report physical and any abuse $(P<0.001)$. Child abuse was less likely among respondents who were divorced, separated, and widowed than among respondents who were married or in common-law relationship. Those with low- and middle- income were more likely to have a history of abuse in their childhood than people with higher-incomes (\$ 50,000 and more). Most respondents reporting childhood abuse had completed post secondary education $(P<0.05)$. Immigrants were less likely to report a history of sexual abuse $(P<0.001)$.

\section{Prevalence of selected mental disorders by gender}

The lifetime prevalence of internalizing disorders was $12.75 \%$ in men and $20.47 \%$ in women. In contrast, the

Table 2 Socio-demographic profile by types of childhood abuse

\begin{tabular}{|c|c|c|c|c|c|c|c|c|c|c|c|c|}
\hline \multirow[t]{2}{*}{ Selected characteristics } & \multicolumn{3}{|c|}{ Physical abuse (\%) } & \multicolumn{3}{|c|}{ Sexual abuse (\%) } & \multicolumn{3}{|c|}{ Exposure to interpersonal violence (\%) } & \multicolumn{3}{|c|}{ Any abuse (\%) } \\
\hline & No & Yes & $P$ & No & Yes & $P$ & No & Yes & $P$ & No & Yes & $P$ \\
\hline$\overline{\text { Age }}$ & & & $<0.001$ & & & $<0.001$ & & & $<0.001$ & & & $<0.001$ \\
\hline $18-24$ & 13.57 & 8.56 & & 12.26 & 4.92 & & 11.88 & 9.38 & & 13.94 & 8.67 & \\
\hline $25-44$ & 33.15 & 36.25 & & 35.00 & 30.40 & & 33.76 & 39.30 & & 32.97 & 36.13 & \\
\hline $45-64$ & 33.02 & 39.96 & & 34.75 & 45.71 & & 35.39 & 39.41 & & 32.67 & 39.62 & \\
\hline $65+$ & 20.26 & 15.23 & & 17.99 & 18.97 & & 18.97 & 11.92 & & 20.42 & 15.58 & \\
\hline Gender & & & $<0.001$ & & & $<0.001$ & & & 0.100 & & & $<0.001$ \\
\hline Male & 45.20 & 55.21 & & 51.51 & 30.90 & & 49.50 & 46.87 & & 46.37 & 52.78 & \\
\hline Female & 54.80 & 44.79 & & 48.49 & 69.10 & & 50.50 & 53.13 & & 53.63 & 47.22 & \\
\hline Marital Status & & & $<0.001$ & & & $<0.001$ & & & 0.418 & & & $<0.001$ \\
\hline Married/Common law & 56.76 & 64.92 & & 59.71 & 63.22 & & 63.28 & 62.46 & & 55.99 & 65.00 & \\
\hline Single & 30.64 & 21.69 & & 27.95 & 19.11 & & 23.38 & 22.85 & & 31.65 & 21.41 & \\
\hline Divorced/Separated/Widowed & 12.59 & 13.38 & & 12.34 & 17.68 & & 13.34 & 14.70 & & 12.36 & 13.58 & \\
\hline Income & & & $<0.001$ & & & $<0.001$ & & & $<0.001$ & & & $<0.001$ \\
\hline$<15,000$ & 25.97 & 17.99 & & 22.38 & 24.09 & & 19.05 & 23.51 & & 26.40 & 18.32 & \\
\hline $15,000-29,999$ & 21.53 & 20.49 & & 20.44 & 26.21 & & 21.37 & 23.87 & & 20.87 & 21.32 & \\
\hline $30,000-49,999$ & 23.12 & 24.03 & & 23.58 & 22.95 & & 24.72 & 22.02 & & 23.21 & 23.84 & \\
\hline $50,000-69,999$ & 13.66 & 16.12 & & 14.85 & 13.53 & & 15.58 & 14.10 & & 13.76 & 15.75 & \\
\hline $70,000-89,999$ & 7.39 & 9.58 & & 8.58 & 6.29 & & 8.66 & 8.75 & & 7.21 & 9.56 & \\
\hline $90,000+$ & 8.34 & 11.79 & & 10.17 & 6.94 & & 10.62 & 7.76 & & 8.55 & 11.21 & \\
\hline Education & & & $<0.001$ & & & 0.039 & & & $<0.001$ & & & $<0.001$ \\
\hline Less than secondary & 21.84 & 12.72 & & 18.21 & 17.35 & & 14.17 & 16.89 & & 22.28 & 13.13 & \\
\hline Secondary graduation & 16.39 & 14.87 & & 16.06 & 13.36 & & 16.37 & 16.83 & & 16.45 & 14.95 & \\
\hline Some post secondary & 6.80 & 7.58 & & 6.96 & 8.40 & & 6.45 & 8.97 & & 6.53 & 7.81 & \\
\hline Post secondary & 54.97 & 64.83 & & 58.77 & 60.90 & & 63.01 & 57.30 & & 54.73 & 64.11 & \\
\hline Place of residence & & & 0.181 & & & 0.236 & & & 0.143 & & & 0.404 \\
\hline Urban & 81.94 & 83.24 & & 82.63 & 81.15 & & 82.19 & 84.00 & & 82.12 & 82.90 & \\
\hline Rural & 18.06 & 16.76 & & 17.37 & 18.85 & & 17.81 & 16.00 & & 17.88 & 17.10 & \\
\hline Immigrant & & & 0.218 & & & $<0.001$ & & & 0.161 & & & 0.054 \\
\hline Yes & 25.67 & 24.39 & & 25.76 & 20.01 & & 25.45 & 27.47 & & 26.05 & 24.07 & \\
\hline No & 74.33 & 75.61 & & 74.24 & 79.99 & & 74.55 & 72.53 & & 73.95 & 75.93 & \\
\hline
\end{tabular}


lifetime prevalence of substance use disorders was $30.36 \%$ in men and only $12.24 \%$ in women. The past 12 -month prevalence of internalizing disorders was $5.24 \%$ among men and $7.71 \%$ among women. The past 12 -month prevalence of substance use disorders was $6.19 \%$ among men and $2.42 \%$ among women. Table 3 presents prevalence rates for individual mental disorder by gender.

\section{Prevalence of selected mental disorders by types of childhood abuse}

Childhood abuse was consistently associated with the increased risk of the studied mental disorders $(P<0.001)$. There were significant associations between different types of childhood abuse and individual mental disorders. Table 4 shows the detailed relations between types of childhood abuse and mental disorders. Some of $23.62 \%$ of people with any abuse in the childhood were determined to have had an internalizing problem during their lifetime. There were $30.62 \%$ of people with any abuse who had a lifetime externalizing disorder.
Relationships between mental disorders and childhood abuse moderated by gender

Interactions between gender and different types of child abuse were tested for each mental disorder without and with adjusting for socio-demographic variables. Table 5 summarizes the significant interactions between gender and type of child abuse for selected mental disorders. Significant interactions were found between being female and sexual abuse for alcohol abuse or dependence (adjusted OR for the interaction: 1.46, 95 \% CI 1.04-2.04) and between being female and exposure to interpersonal violence for alcohol abuse or dependence (adjusted OR for the interaction: 1.41, 95 \% CI 1.06-1.86). Though, females were less likely to have alcohol abuse or dependence or substance use disorders, after adjusting other socio-demographic variables, the statistical interactions between sexual abuse and exposure to interpersonal violence and being female indicate persons with these combinations of attributes were more likely to report suffering from alcohol abuse or dependence. Tables 6, 7, 8, and 9 in Appendix provides details on the interactions being female, types of child abuse and specific psychiatric diagnoses.

Table 3 Prevalence of selected mental disorders by gender

\begin{tabular}{|c|c|c|c|c|c|}
\hline \multirow[t]{2}{*}{ Selected mental disorders } & \multicolumn{2}{|l|}{ Men } & \multicolumn{2}{|c|}{ Women } & \multirow[t]{2}{*}{$P$-value } \\
\hline & $\%$ & $95 \% \mathrm{Cl}^{\mathrm{a}}$ & $\%$ & $95 \% \mathrm{Cl}$ & \\
\hline \multicolumn{6}{|l|}{ Internalizing disorders lifetime } \\
\hline Bipolar disorder & 2.71 & $2.33-3.16$ & 2.53 & $2.11-3.03$ & 0.559 \\
\hline Depression & 8.49 & $7.73-9.32$ & 14.05 & $13.10-15.06$ & $<0.001$ \\
\hline Generalized anxiety disorder & 6.04 & $5.46-6.68$ & 11.32 & $10.42-12.28$ & $<0.001$ \\
\hline Hypomania & 1.81 & $1.50-2.18$ & 1.69 & $1.35-2.12$ & 0.658 \\
\hline Mania & 2.71 & $2.32-3.15$ & 2.53 & $2.11-3.03$ & 0.574 \\
\hline Mood disorder & 10.03 & $9.20-10.93$ & 15.06 & $14.09-16.10$ & $<0.001$ \\
\hline Any kind of internalizing disorders & 12.75 & $11.85-13.70$ & 20.47 & $19.31-21.69$ & $<0.001$ \\
\hline \multicolumn{6}{|l|}{ Internalizing disorders 12-month } \\
\hline Bipolar disorder & 1.58 & $1.28-1.96$ & 1.44 & $1.13-1.82$ & 0.551 \\
\hline Depression & 3.62 & $3.17-4.14$ & 5.79 & $5.15-6.52$ & $<0.001$ \\
\hline Generalized anxiety disorder & 1.95 & $1.62-2.35$ & 3.17 & $2.75-3.64$ & $<0.001$ \\
\hline Hypomania & 0.98 & $0.74-1.30$ & 0.74 & $0.55-0.99$ & 0.176 \\
\hline Mania & 0.91 & $0.68-1.21$ & 1.11 & $0.85-1.45$ & 0.312 \\
\hline Mood disorder & 4.37 & $3.86-4.95$ & 6.41 & $5.74-7.16$ & $<0.001$ \\
\hline Any kind of internalizing disorders & 5.24 & $4.67-5.87$ & 7.71 & $7.00-8.49$ & $<0.001$ \\
\hline \multicolumn{6}{|l|}{ Externalizing disorders lifetime } \\
\hline Alcohol abuse or dependence & 26.60 & $25.28-27.97$ & 9.83 & $9.08-10.64$ & $<0.001$ \\
\hline Drug abuse or dependence & 11.64 & $10.70-12.66$ & 5.56 & $4.99-6.20$ & $<0.001$ \\
\hline Any kind of externalizing disorders & 30.36 & $28.96-31.80$ & 12.24 & $11.37-13.16$ & $<0.001$ \\
\hline \multicolumn{6}{|l|}{ Externalizing disorders 12-month } \\
\hline Alcohol abuse or dependence & 4.67 & $4.09-5.34$ & 1.71 & $1.42-2.04$ & $<0.001$ \\
\hline Drug abuse or dependence & 2.51 & $2.15-2.93$ & 1.07 & $0.86-1.34$ & $<0.001$ \\
\hline Any kind of externalizing disorders & 6.19 & $5.55-6.91$ & 2.42 & $2.08-2.82$ & $<0.001$ \\
\hline
\end{tabular}

${ }^{\mathrm{a}} 95 \% \mathrm{Cl}=95 \%$ confidence interval 
Table 4 Prevalence of selected mental disorders by types of childhood abuse ${ }^{a}$

\begin{tabular}{|c|c|c|c|c|}
\hline \multirow[t]{2}{*}{ Selected mental disorders } & Physical abuse & Sexual abuse & Exposure to parent hit other adult & Any abuse \\
\hline & $\%(95 \% \mathrm{Cl})^{\mathrm{b}}$ & $\%(95 \% \mathrm{Cl})$ & $\%(95 \% \mathrm{Cl})$ & $\%(95 \% \mathrm{Cl})$ \\
\hline \multicolumn{5}{|l|}{ Internalizing disorders lifetime } \\
\hline Bipolar disorder & $3.90(3.33-4.56)$ & $5.82(4.77-7.09)$ & $6.55(5.24-8.16)$ & $3.97(3.43-4.59)$ \\
\hline Depression & $16.12(14.98-17.34)$ & $11.31(10.69-11.96)$ & $19.01(16.99-21.21)$ & $16.42(15.32-17.58)$ \\
\hline Generalized anxiety disorder & $12.72(11.77-13.73)$ & $19.91(17.76-22.25)$ & $15.58(13.84-17.50)$ & $12.79(11.89-13.75)$ \\
\hline Hypomania & $2.48(2.03-3.03)$ & $3.51(2.74-4.48)$ & $4.30(3.20-5.76)$ & $2.51(2.08-3.03)$ \\
\hline Mania & $3.88(3.31-4.54)$ & $5.95(4.89-7.23)$ & $6.48(5.18-8.09)$ & $3.95(3.41-4.57)$ \\
\hline Mood disorder & $17.97(16.80-19.20)$ & $27.89(25.27-30.67)$ & $22.20(20.05-24.52)$ & 18.32 (17.19-19.50) \\
\hline Any kind of internalizing disorders & $23.25(21.97-24.58)$ & $35.17(32.29-38.16)$ & $28.59(26.24-31.07)$ & 23.62 (22.39-24.89) \\
\hline \multicolumn{5}{|l|}{ Internalizing disorders 12-month } \\
\hline Bipolar disorder & $2.45(2.02-2.98)$ & $3.55(2.72-4.63)$ & $3.59(2.77-4.64)$ & $2.38(1.98-2.85)$ \\
\hline Depression & $7.08(6.31-7.93)$ & $11.40(9.55-13.55)$ & $9.01(7.64-10.59)$ & $6.95(6.25-7.71)$ \\
\hline Generalized anxiety disorder & $3.87(3.38-4.42)$ & $6.23(5.25-7.38)$ & $5.28(4.33-6.44)$ & $3.83(3.37-4.35)$ \\
\hline Hypomania & $1.32(1.03-1.69)$ & $1.68(1.24-2.28)$ & $2.33(1.71-3.17)$ & $1.29(1.03-1.63)$ \\
\hline Mania & $1.65(1.30-2.10)$ & $2.43(1.88-3.12)$ & $2.33(1.77-3.05)$ & $1.60(1.27-2.00)$ \\
\hline Mood disorder & $8.19(7.39-9.06)$ & $12.98(11.08-15.14)$ & $10.69(9.26-12.32)$ & $8.03(7.31-8.81)$ \\
\hline Any kind of internalizing disorders & $9.66(8.81-10.57)$ & $14.83(12.88-17.03)$ & $12.62(11.10-14.31)$ & $9.44(8.68-10.26)$ \\
\hline \multicolumn{5}{|l|}{ Externalizing disorders lifetime } \\
\hline Alcohol abuse or dependence & $27.26(25.82-28.75)$ & $24.61(22.33-27.04)$ & $27.57(25.40-29.84)$ & $26.19(24.86-27.57)$ \\
\hline Drug abuse or dependence & $14.21(13.02-15.49)$ & $16.06(13.95-18.42)$ & $16.48(14.43-18.75)$ & $13.56(12.47-14.72)$ \\
\hline Any kind of externalizing disorder & $31.77(30.20-33.38)$ & $29.69(27.15-32.36)$ & $33.00(30.50-35.60)$ & $30.62(29.15-32.13)$ \\
\hline \multicolumn{5}{|l|}{ Externalizing disorders 12 -month } \\
\hline Alcohol abuse or dependence & $4.40(3.82-5.08)$ & $4.08(2.99-5.54)$ & $4.71(3.72-5.96)$ & $4.10(3.57-4.72)$ \\
\hline Drug abuse or dependence & $2.50(2.11-2.97)$ & $2.73(2.02-3.68)$ & $3.06(2.37-3.94)$ & $2.44(2.07-2.86)$ \\
\hline Any kind of externalizing disorder & $5.87(5.21-6.62)$ & $5.31(4.14-6.78)$ & $6.67(5.54-8.01)$ & $5.57(4.96-6.24)$ \\
\hline
\end{tabular}

${ }^{\mathrm{a}} P<0.001$

${ }^{b} 95 \% \mathrm{Cl}=95 \%$ confidence interval

Table 5 Significant relationships between studied mental disorders and childhood abuse moderated by female gender

\begin{tabular}{|c|c|c|c|c|c|c|}
\hline \multirow[t]{2}{*}{ Childhood abuse and mental disorders } & \multicolumn{2}{|l|}{ Type of abuse } & \multicolumn{2}{|l|}{ Female gender } & \multicolumn{2}{|l|}{ Interactions $^{b}$} \\
\hline & OR $(95 \%$ Cl) & $P$-value & OR $(95 \% \mathrm{Cl})$ & $P$-value & OR $(95 \% \mathrm{Cl})$ & $P$-value \\
\hline \multicolumn{7}{|l|}{ Physical abuse } \\
\hline Alcohol abuse or dependence past 12-month & $1.56(1.16-2.09)$ & 0.003 & $0.29(0.21-0.41)$ & $<0.001$ & $1.57(1.00-2.48)$ & 0.05 \\
\hline Alcohol abuse or dependence past 12-month ${ }^{\mathrm{a}}$ & $1.97(1.37-2.85)$ & $<0.001$ & $0.29(0.19-0.43)$ & $<0.001$ & $1.51(0.87-2.59)$ & 0.13 \\
\hline \multicolumn{7}{|l|}{ Sexual abuse } \\
\hline Alcohol abuse or dependence lifetime & $1.66(1.30-2.12)$ & $<0.001$ & $0.26(0.23-0.29)$ & $<0.001$ & $1.60(1.17-2.19)$ & 0.003 \\
\hline Alcohol abuse or dependence lifetime ${ }^{a}$ & $1.66(1.27-2.17)$ & $<0.001$ & $0.25(0.22-0.29)$ & $<0.001$ & $1.46(1.04-2.04)$ & 0.03 \\
\hline Externalizing problems lifetime & $1.89(1.46-2.44)$ & $<0.001$ & $0.28(0.25-0.31)$ & $<0.001$ & $1.39(1.02-1.90)$ & 0.04 \\
\hline Externalizing problems lifetime ${ }^{a}$ & $2.09(1.59-2.75)$ & $<0.001$ & $0.26(0.23-0.29)$ & $<0.001$ & $1.19(0.85-1.67)$ & 0.31 \\
\hline \multicolumn{7}{|l|}{ Exposure to "parent hit other adult" } \\
\hline Alcohol abuse or dependence lifetime & $1.65(1.40-1.95)$ & $<0.001$ & $0.25(0.22-0.29)$ & $<0.001$ & $1.57(1.20-2.06)$ & 0.001 \\
\hline Alcohol abuse or dependence lifetime ${ }^{a}$ & $1.74(1.45-2.08)$ & $<0.001$ & $0.26(0.23-0.29)$ & $<0.001$ & $1.41(1.06-1.86)$ & 0.02 \\
\hline Externalizing problems lifetime & $1.89(1.58-2.25)$ & $<0.001$ & $0.28(0.25-0.31)$ & $<0.001$ & $1.36(1.04-1.76)$ & 0.02 \\
\hline Externalizing problems lifetime ${ }^{a}$ & $2.03(1.68-2.44)$ & $<0.001$ & $0.27(0.24-0.31)$ & $<0.001$ & $1.19(0.90-1.57)$ & 0.23 \\
\hline
\end{tabular}




\section{Discussion}

\section{Main findings}

What this national population survey shows is: 1) strong associations between childhood abuse frequency and gender, with men reporting frequent physical abuse, exposure to interpersonal violence, and any abuse, women more frequently reported sexual abuse; 2) significant differences between men and women in terms of mental disorders, with men having a higher prevalence of substance use disorders and women a higher prevalence of internalizing disorders; 3) strong associations between childhood abuse and mental disorders; 4) after adjusted for socio-demographic variables there were significant statistical interactions between being female and both sexual abuse and exposure to interpersonal violence for alcohol abuse or dependence. Abuse in childhood has a differential impact on females than males.

Although the measurement of child abuse (including its subtypes) may be varied across studies, the major findings of the present study are consistent with previous literature. Studies have consistently showed that childhood abuse is associated with negative mental health outcomes, for example, internalizing disorders [24, 25], externalizing disorders $[26,27]$, etc. Epidemiological data have also consistently pointed out that there is gender difference in risk of childhood abuse with women are more likely to report a history of childhood sexual abuse [28-30], whereas men are more likely to report physical abuse [8]. The findings for other types of childhood abuse are mixed [22]. Similarly, gender differences have also been identified in many studies of the prevalence and incidence of mental disorders with men having more externalizing disorders, such as alcohol abuse $[18,31,32]$, and women having more internalizing disorders, such as depression and anxiety [33, 34].

Notably, in this large-scale population analysis, we found that even though females had a lower risk of substance use disorders, the moderating role of being female in the relationship between sexual abuse and/or exposure to interpersonal violence and substance use disorders significantly increased the vulnerability of females having substance use disorders. Similarly, the interaction between being female and a history of child abuse significantly increased the likelihood of alcohol problems [35]. Consistent with our findings of significant interactions between being female and childhood abuse, a prospective study of African-American women over 20-year period found that childhood sexual abuse was an important predictor of heavy alcohol use and binge drinking in adulthood [36]. A review on child sexual and physical abuse and alcoholism suggested females were more likely to have alcohol problems when they had been exposed to sexual or physical abuse as children, but there was not sufficient evidence to support a similar conclusion for males [37]. There have been numerous studies into the negative impact of child abuse on psychological well-being [38], self-harm [39], self-esteem [40], life satisfaction [41], etc. The moderating role of female gender in the abusesubstance use relationship could be explained by: i) the use of substances as self-medication in an attempt to control over the negative experience; ii) substance use is a way of exhibiting self-destructive behaviour. Therefore, it is important to anticipate the link between the history of childhood sexual abuse and/or exposure to interpersonal violence and adulthood substance use disorders among female child abuse victims. Factors such as positive or adaptive coping skills may help mediate the relationship between childhood victimization and substance use problems. Implications of this finding is that intervention should occur as early as possible, and should be focused on females, who have been sexually abused or exposed to interpersonal violence, and their families to learn more constructive ways of coping with the negative affects that are associated with these adverse experiences.

\section{Strengths and limitations}

This study has several methodological strengths: 1) data used was from a large population-based sample broadly representative of the Canadian population, therefore findings of this study are more reliable and highly generalizable; 2) this study explored interactions between different types of childhood abuse and gender in several selected mental disorders. However the limitations of the study are: 1) the survey is cross-sectional, therefore no causal inferences between childhood abuse and mental disorders could be made; 2) the survey may have recall bias, as childhood abuse was based on retrospective self-reports; 3) though the survey was designed to explore major mental health problems in Canada only the more common mental disorders were assessed.

\section{Conclusions}

Gender differences both in mental disorders and in different types of child abuse exist in the Canadian population. Gender moderated the role of childhood abuse history on adulthood mental disorders. Females with a history of sexual abuse and/ or exposure to interpersonal violence were at a greater risk of alcohol abuse or dependence. It is important to anticipate the link between the history of childhood sexual abuse and/or exposure to interpersonal violence and adulthood substance use disorders among female victims. Factors such as positive and adaptive coping skills may help mediate the relationship between childhood victimization and substance use problems. Earlier interventions should focus on positive and adaptive coping skills to effectively reduce the onset of substance use problems among female victims. In providing optimal care for those with alcohol abuse disorders it is important to recognize and understand the different mechanisms of action and impact of childhood maltreatment for women and men. 


\section{Appendix}

Table 6 Multivariate analysis for interactions between physical abuse, being female and selected mental disorders

\begin{tabular}{|c|c|c|c|c|c|c|}
\hline \multirow[t]{2}{*}{ Selected mental disorders } & \multicolumn{2}{|l|}{ Physical abuse } & \multicolumn{2}{|l|}{ Female gender } & \multicolumn{2}{|l|}{ Interactions } \\
\hline & OR $(95 \% \mathrm{Cl})$ & $P$-value & $\mathrm{OR}(95 \% \mathrm{Cl})$ & $P$-value & OR $(95 \% \mathrm{Cl})$ & $P$-value \\
\hline \multicolumn{7}{|l|}{ Internalizing disorders lifetime } \\
\hline Bipolar disorder & $2.11(1.49-3.00)$ & $<0.001$ & $0.91(0.62-1.35)$ & 0.65 & $1.18(0.71-1.95)$ & 0.52 \\
\hline Bipolar disorder ${ }^{a}$ & $2.66(1.77-3.99)$ & $<0.001$ & $0.84(0.53-1.33)$ & 0.45 & $0.96(0.55-1.67)$ & 0.87 \\
\hline Depression & $2.29(1.87-2.79)$ & $<0.001$ & $1.87(1.54-2.28)$ & $<0.001$ & $1.07(0.83-1.38)$ & 0.63 \\
\hline Depression $^{a}$ & $2.52(2.04-3.13)$ & $<0.001$ & $1.85(1.48-2.32)$ & $<0.001$ & $0.90(0.68-1.18)$ & 0.45 \\
\hline Generalized anxiety disorder & $2.24(1.80-2.79)$ & $<0.001$ & $1.99(1.58-2.50)$ & $<0.001$ & $1.18(0.89-1.58)$ & 0.25 \\
\hline Generalized anxiety disorder ${ }^{a}$ & $2.20(1.74-2.79)$ & $<0.001$ & $1.83(1.42-2.37)$ & $<0.001$ & $1.09(0.80-1.48)$ & 0.58 \\
\hline Hypomania & $1.84(1.22-2.76)$ & 0.004 & $0.90(0.57-1.42)$ & 0.65 & $1.21(0.66-2.22)$ & 0.54 \\
\hline Hypomania $^{a}$ & $2.42(1.53-3.83)$ & $<0.001$ & $0.85(0.49-1.49)$ & 0.58 & $0.92(0.47-1.80)$ & 0.81 \\
\hline Mania & $2.07(1.46-2.94)$ & $<0.001$ & $0.91(0.62-1.34)$ & 0.64 & $1.19(0.72-1.97)$ & 0.50 \\
\hline Mania $^{a}$ & $2.63(1.75-3.95)$ & $<0.001$ & $0.84(0.53-1.33)$ & 0.46 & $0.95(0.54-1.67)$ & 0.86 \\
\hline Mood disorder & $2.30(1.91-2.77)$ & $<0.001$ & $1.69(1.41-2.03)$ & $<0.001$ & $1.06(0.83-1.35)$ & 0.63 \\
\hline Mood disorder ${ }^{a}$ & $2.62(2.14-3.21)$ & $<0.001$ & $1.71(1.38-2.12)$ & $<0.001$ & $0.87(0.67-1.13)$ & 0.30 \\
\hline Any kind of internalizing disorders & $2.22(1.89-2.60)$ & $<0.001$ & $1.83(1.55-2.16)$ & $<0.001$ & $1.12(0.90-1.39)$ & 0.31 \\
\hline Any kind of internalizing disorders ${ }^{a}$ & $2.40(2.01-2.85)$ & $<0.001$ & $1.85(1.53-2.22)$ & $<0.001$ & $0.95(0.75-1.20)$ & 0.67 \\
\hline \multicolumn{7}{|l|}{ Internalizing disorders 12-month } \\
\hline Bipolar disorder & $2.83(1.74-4.59)$ & $<0.001$ & $0.97(0.56-1.69)$ & 0.93 & $1.05(0.51-2.14)$ & 0.90 \\
\hline Bipolar disorder ${ }^{a}$ & $4.00(2.25-7.11)$ & $<0.001$ & $0.94(0.47-1.90)$ & 0.87 & $0.80(0.35-1.79)$ & 0.58 \\
\hline Depression & $2.59(1.90-3.53)$ & $<0.001$ & $1.85(1.38-2.48)$ & $<0.001$ & $0.96(0.65-1.41)$ & 0.83 \\
\hline Depression $^{a}$ & $3.02(2.16-4.21)$ & $<0.001$ & $1.49(1.05-2.12)$ & 0.03 & $0.88(0.58-1.33)$ & 0.54 \\
\hline Generalized anxiety disorder & $2.12(1.43-3.13)$ & $<0.001$ & $1.53(1.03-2.28)$ & 0.03 & $1.30(0.80-2.11)$ & 0.30 \\
\hline Generalized anxiety disorder ${ }^{a}$ & $2.14(1.37-3.35)$ & 0.001 & $1.18(0.75-1.87)$ & 0.47 & $1.20(0.69-2.07)$ & 0.51 \\
\hline Hypomania & $2.84(1.54-5.23)$ & 0.001 & $1.01(0.52-1.99)$ & 0.97 & $0.71(0.30-1.67)$ & 0.43 \\
\hline Hypomania $^{a}$ & $5.14(2.67-9.86)$ & $<0.001$ & $1.33(0.59-3.03)$ & 0.49 & $0.41(0.16-1.04)$ & 0.06 \\
\hline Mania & $3.40(1.79-6.46)$ & $<0.001$ & $1.56(0.75-3.25)$ & 0.24 & $0.82(0.33-2.07)$ & 0.68 \\
\hline Mania $^{a}$ & $6.27(3.00-13.07)$ & $<0.001$ & $2.14(0.88-5.19)$ & 0.09 & $0.44(0.16-1.19)$ & 0.11 \\
\hline Mood disorder & $2.72(2.05-3.62)$ & $<0.001$ & $1.74(1.31-2.30)$ & $<0.001$ & $0.92(0.64-1.32)$ & 0.66 \\
\hline Mood disorder ${ }^{a}$ & $3.37(2.78-4.58)$ & $<0.001$ & $1.52(1.08-2.14)$ & 0.02 & $0.78(0.53-1.16)$ & 0.22 \\
\hline Any kind of internalizing disorders & $2.41(1.89-3.07)$ & $<0.001$ & $1.60(1.25-2.05)$ & $<0.001$ & $1.06(0.77-1.46)$ & 0.70 \\
\hline Any kind of internalizing disorders ${ }^{a}$ & $2.88(2.20-3.77)$ & $<0.001$ & $1.38(1.04-1 . .84)$ & 0.03 & $0.91(0.64-1.93)$ & 0.58 \\
\hline \multicolumn{7}{|l|}{ Externalizing disorders lifetime } \\
\hline Alcohol abuse or dependence & $2.54(2.22-2.89)$ & $<0.001$ & $0.30(0.26-0.36)$ & $<0.001$ & $1.10(0.88-1.38)$ & 0.41 \\
\hline Alcohol abuse or dependence ${ }^{a}$ & $2.44(2.10-2.84)$ & $<0.001$ & $0.30(0.25-0.35)$ & $<0.001$ & $1.03(0.81-1.32)$ & 0.79 \\
\hline Drug abuse or dependence & $3.07(2.56-3.69)$ & $<0.001$ & $0.46(0.38-0.57)$ & $<0.001$ & $1.10(0.83-1.45)$ & 0.51 \\
\hline Drug abuse or dependence ${ }^{a}$ & $3.39(2.76-4.18)$ & $<0.001$ & $0.42(0.33-0.53)$ & $<0.001$ & $0.98(0.71-1.36)$ & 0.91 \\
\hline Any kind of externalizing disorders & $2.69(2.37-3.05)$ & $<0.001$ & $0.33(0.29-0.38)$ & $<0.001$ & $1.04(0.85-1.28)$ & 0.68 \\
\hline Any kind of externalizing disorders ${ }^{a}$ & $2.74(2.37-3.17)$ & $<0.001$ & $0.31(0.26-0.37)$ & $<0.001$ & $0.96(0.76-1.21)$ & 0.72 \\
\hline \multicolumn{7}{|l|}{ Externalizing disorders 12-month } \\
\hline Alcohol abuse or dependence & $1.56(1.16-2.09)$ & 0.003 & $0.29(0.21-0.41)$ & $<0.001$ & $1.57(1.00-2.48)$ & 0.05 \\
\hline Alcohol abuse or dependence ${ }^{a}$ & $1.97(1.37-2.85)$ & $<0.001$ & $0.29(0.19-0.43)$ & $<0.001$ & $1.51(0.87-2.59)$ & 0.13 \\
\hline Drug abuse or dependence & $1.94(1.39-2.73)$ & $<0.001$ & $0.50(0.33-0.74)$ & 0.001 & $0.82(0.46-1.47)$ & 0.51 \\
\hline
\end{tabular}


Table 6 Multivariate analysis for interactions between physical abuse, being female and selected mental disorders (Continued)

\begin{tabular}{lllllll}
\hline Drug abuse or dependence $^{a}$ & $2.91(1.94-4.37)$ & $<0.001$ & $0.36(0.22-0.59)$ & $<0.001$ & $0.83(0.43-1.59)$ & 0.57 \\
Any kind of externalizing disorders & $1.69(1.32-2.17)$ & $<0.001$ & $0.38(0.28-0.49)$ & $<0.001$ & $1.11(0.76-1.62)$ & 0.59 \\
Any kind of externalizing disorders $^{\mathrm{a}}$ & $2.24(1.63-3.06)$ & $<0.001$ & $0.33(0.23-0.45)$ & $<0.001$ & $1.12(0.71-1.75)$ & 0.63 \\
\hline
\end{tabular}

adjusted for age, marital status, income, education, place of residence, immigrant

Table 7 Multivariate analysis for interactions between sexual abuse being female and selected mental disorders

\begin{tabular}{|c|c|c|c|c|c|c|}
\hline \multirow[t]{2}{*}{ Selected mental disorders } & \multicolumn{2}{|l|}{ Sexual abuse } & \multicolumn{2}{|l|}{ Female gender } & \multicolumn{2}{|l|}{ Interactions } \\
\hline & OR $(95 \% \mathrm{Cl})$ & $P$-value & OR $(95 \% \mathrm{Cl})$ & $P$-value & OR $(95 \% \mathrm{Cl})$ & $P$-value \\
\hline \multicolumn{7}{|l|}{ Internalizing disorders lifetime } \\
\hline Bipolar disorder & $3.20(2.15-4.76)$ & $<0.001$ & $0.87(0.64-1.17)$ & 0.35 & $0.81(0.46-1.40)$ & 0.45 \\
\hline Bipolar disorder ${ }^{a}$ & $3.54(2.24-5.58)$ & $<0.001$ & $0.72(0.51-1.01)$ & 0.06 & $0.73(0.39-1.37)$ & 0.33 \\
\hline Depression & $2.31(1.71-3.11)$ & $<0.001$ & $1.51(1.31-1.74)$ & $<0.001$ & $1.37(0.96-1.95)$ & 0.09 \\
\hline Depression $^{\mathrm{a}}$ & $2.43(1.76-3.37)$ & $<0.001$ & $1.38(1.18-1.63)$ & $<0.001$ & $1.20(0.82-1.75)$ & 0.36 \\
\hline Generalized anxiety disorder & $2.74(2.02-3.71)$ & $<0.001$ & $1.78(1.52-2.09)$ & $<0.001$ & $1.03(0.73-1.47)$ & 0.85 \\
\hline Generalized anxiety disorder ${ }^{a}$ & $2.64(1.87-3.72)$ & $<0.001$ & $1.62(1.36-1.94)$ & $<0.001$ & $0.94(0.63-1.40)$ & 0.78 \\
\hline Hypomania & $3.33(2.04-5.46)$ & $<0.001$ & $0.95(0.66-1.37)$ & 0.80 & $0.57(0.30-1.08)$ & 0.09 \\
\hline Hypomania $^{a}$ & $3.86(2.28-6.54)$ & $<0.001$ & $0.81(0.53-1.24)$ & 0.34 & $0.49(0.24-1.04)$ & 0.05 \\
\hline Mania & $3.30(2.23-4.90)$ & $<0.001$ & $0.87(0.64-1.17)$ & 0.35 & $0.81(0.47-1.40)$ & 0.44 \\
\hline Mania $^{a}$ & $3.69(2.35-5.82)$ & $<0.001$ & $0.72(0.51-1.02)$ & 0.06 & $0.72(0.38-1.34)$ & 0.30 \\
\hline Mood disorder & $2.50(1.90-3.29)$ & $<0.001$ & $1.37(1.20-1.56)$ & $<0.001$ & $1.30(0.94-1.80)$ & 0.12 \\
\hline Mood disorder ${ }^{a}$ & $2.72(2.00-3.70)$ & $<0.001$ & $1.26(1.08-1.47)$ & 0.003 & $1.13(0.79-1.62)$ & 0.50 \\
\hline Any kind of internalizing disorders & $2.43(1.89-3.13)$ & $<0.001$ & $1.53(1.36-1.73)$ & $<0.001$ & $1.32(0.98-1.78)$ & 0.07 \\
\hline Any kind of internalizing disorders ${ }^{a}$ & $2.58(1.94-3.42)$ & $<0.001$ & $1.44(1.26-1.65)$ & $<0.001$ & $1.18(0.84-1.66)$ & 0.33 \\
\hline \multicolumn{7}{|l|}{ Internalizing disorders 12-month } \\
\hline Bipolar disorder & $3.21(1.94-5.30)$ & $<0.001$ & $0.82(0.55-1.22)$ & 0.32 & $0.90(0.45-1.81)$ & 0.77 \\
\hline Bipolar disorder ${ }^{a}$ & $3.32(1.84-6.01)$ & $<0.001$ & $0.66(0.41-1.07)$ & 0.09 & $0.87(0.40-1.92)$ & 0.74 \\
\hline Depression & $2.84(1.86-4.34)$ & $<0.001$ & $1.44(1.17-1.78)$ & 0.001 & $1.05(0.63-1.73)$ & 0.86 \\
\hline Depression $^{a}$ & $2.81(1.77-4.84)$ & $<0.001$ & $1.09(0.85-1.41)$ & 0.49 & $1.09(0.63-1.88)$ & 0.77 \\
\hline Generalized anxiety disorder & $3.20(2.02-5.06)$ & $<0.001$ & $1.52(1.14-2.01)$ & 0.004 & $0.84(0.50-1.43)$ & 0.52 \\
\hline Generalized anxiety disorder $^{\mathrm{a}}$ & $2.81(1.69-4.67)$ & $<0.001$ & $1.16(0.85-1.59)$ & 0.35 & $0.83(0.46-1.49)$ & 0.53 \\
\hline Hypomania & $3.03(1.65-5.57)$ & $<0.001$ & $0.75(0.46-1.23)$ & 0.25 & $0.65(0.30-1.43)$ & 0.29 \\
\hline Hypomania $^{a}$ & $3.83(2.04-7.18)$ & $<0.001$ & $0.66(0.35-1.25)$ & 0.21 & $0.56(0.24-1.30)$ & 0.18 \\
\hline Mania & $3.84(2.06-7.16)$ & $<0.001$ & $1.20(0.74-1.96)$ & 0.46 & $0.64(0.29-1.39)$ & 0.26 \\
\hline Mania $^{a}$ & $3.76(1.82-7.74)$ & $<0.001$ & $1.07(0.60-1.90)$ & 0.81 & $0.54(0.22-1.33)$ & 0.18 \\
\hline Mood disorder & $2.91(1.98-4.26)$ & $<0.001$ & $1.32(1.07-1.62)$ & 0.01 & $1.04(0.66-1.65)$ & 0.86 \\
\hline Mood disorder ${ }^{a}$ & $3.00(1.95-4.60)$ & $<0.001$ & $1.03(0.80-1.32)$ & 0.82 & $1.07(0.64-1.77)$ & 0.80 \\
\hline Any kind of internalizing disorders & $2.85(1.99-4.08)$ & $<0.001$ & $1.36(1.13-1.63)$ & 0.001 & $0.99(0.65-1.52)$ & 0.96 \\
\hline Any kind of internalizing disorders ${ }^{a}$ & $2.82(1.88-4.23)$ & $<0.001$ & $1.05(0.85-1.31)$ & 0.64 & $1.04(0.65-1.66)$ & 0.88 \\
\hline \multicolumn{7}{|l|}{ Externalizing disorders lifetime } \\
\hline Alcohol abuse or dependence & $1.66(1.30-2.12)$ & $<0.001$ & $0.26(0.23-0.29)$ & $<0.001$ & $1.60(1.17-2.19)$ & 0.003 \\
\hline Alcohol abuse or dependence ${ }^{a}$ & $1.66(1.27-2.17)$ & $<0.001$ & $0.25(0.22-0.29)$ & $<0.001$ & $1.46(1.04-2.04)$ & 0.03 \\
\hline Drug abuse or dependence & $2.60(1.88-3.59)$ & $<0.001$ & $0.38(0.32-0.45)$ & $<0.001$ & $1.22(0.81-1.85)$ & 0.34 \\
\hline Drug abuse or dependence ${ }^{a}$ & $2.96(2.05-4.27)$ & $<0.001$ & $0.34(0.28-0.41)$ & $<0.001$ & $1.01(0.63-1.62)$ & 0.96 \\
\hline Any kind of externalizing disorders & $1.89(1.46-2.44)$ & $<0.001$ & $0.28(0.25-0.31)$ & $<0.001$ & $1.39(1.02-1.90)$ & 0.04 \\
\hline Any kind of externalizing disorders ${ }^{a}$ & $2.09(1.59-2.75)$ & $<0.001$ & $0.26(0.23-0.29)$ & $<0.001$ & $1.19(0.85-1.67)$ & 0.31 \\
\hline
\end{tabular}


Table 7 Multivariate analysis for interactions between sexual abuse being female and selected mental disorders (Continued)

\begin{tabular}{|c|c|c|c|c|c|c|}
\hline \multicolumn{7}{|l|}{ Externalizing disorders 12-month } \\
\hline Alcohol abuse or dependence & $1.67(0.96-2.91)$ & 0.07 & $0.33(0.26-0.43)$ & $<0.001$ & $1.04(0.54-2.01)$ & 0.90 \\
\hline Alcohol abuse or dependence ${ }^{a}$ & $2.09(1.13-3.87)$ & 0.02 & $0.33(0.25-0.45)$ & $<0.001$ & $0.91(0.44-1.89)$ & 0.80 \\
\hline Drug abuse or dependence & $1.99(1.16-3.42)$ & 0.01 & $0.39(0.28-0.54)$ & $<0.001$ & $1.05(0.51-2.15)$ & 0.90 \\
\hline Drug abuse or dependence ${ }^{a}$ & $2.76(1.54-4.91)$ & 0.001 & $0.27(0.17-0.41)$ & $<0.001$ & $1.09(0.51-2.33)$ & 0.83 \\
\hline Any kind of externalizing disorders & $1.52(0.96-2.42)$ & 0.07 & $0.35(0.28-0.44)$ & $<0.001$ & $1.13(0.65-1.96)$ & 0.67 \\
\hline Any kind of externalizing disorders ${ }^{a}$ & $2.01(1.19-3.39)$ & 0.01 & $0.31(0.24-0.39)$ & $<0.001$ & $1.05(0.56-1.95)$ & 0.88 \\
\hline
\end{tabular}

adjusted for age, marital status, income, education, place of residence, immigrant

Table 8 Multivariate analyses for interactions between interpersonal violence, being female and selected mental disorders

\begin{tabular}{|c|c|c|c|c|c|c|}
\hline \multirow[t]{2}{*}{ Selected mental disorders } & \multicolumn{2}{|c|}{ Exposure to parent hit other adult } & \multicolumn{2}{|l|}{ Female gender } & \multicolumn{2}{|l|}{ Interactions } \\
\hline & OR $(95 \% \mathrm{Cl})$ & $P$-value & $\mathrm{OR}(95 \% \mathrm{Cl})$ & $P$-value & OR $(95 \% \mathrm{Cl})$ & $P$-value \\
\hline \multicolumn{7}{|l|}{ Internalizing disorders lifetime } \\
\hline Bipolar disorder & $3.66(2.54-5.28)$ & $<0.001$ & $0.88(0.65-1.20)$ & 0.43 & $1.08(0.61-1.90)$ & 0.79 \\
\hline Bipolar disorder ${ }^{\mathrm{a}}$ & $3.50(2.32-5.29)$ & $<0.001$ & $0.75(0.54-1.04)$ & 0.09 & $0.93(0.52-1.67)$ & 0.80 \\
\hline Depression & $1.99(1.57-2.52)$ & $<0.001$ & $1.70(1.46-1.98)$ & $<0.001$ & $1.05(0.76-1.46)$ & 0.75 \\
\hline Depression $^{a}$ & $2.04(1.58-2.64)$ & $<0.001$ & $1.59(1.34-1.87)$ & $<0.001$ & $0.95(0.67-1.35)$ & 0.79 \\
\hline Generalized anxiety disorder & $1.93(1.52-2.44)$ & $<0.001$ & $1.84(1.56-2.18)$ & $<0.001$ & $1.19(0.87-1.61)$ & 0.27 \\
\hline Generalized anxiety disorder $^{a}$ & $1.80(1.40-23.32)$ & $<0.001$ & $1.69(1.41-2.04)$ & $<0.001$ & $1.17(0.85-1.62)$ & 0.34 \\
\hline Hypomania & $3.44(2.22-5.32)$ & $<0.001$ & $0.88(0.61-1.26)$ & 0.48 & $1.12(0.56-2.24)$ & 0.74 \\
\hline Hypomania $^{a}$ & $3.49(2.16-5.64)$ & $<0.001$ & $0.76(0.51-1.12)$ & 0.17 & $0.92(0.46-1.83)$ & 0.81 \\
\hline Mania & $3.65(0.52-5.28)$ & $<0.001$ & $0.89(0.66-1.22)$ & 0.48 & $1.06(0.60-1.88)$ & 0.84 \\
\hline Mania $^{a}$ & $3.49(2.31-5.27)$ & $<0.001$ & $0.76(0.54-1.05)$ & 0.10 & $0.91(0.50-1.64)$ & 0.75 \\
\hline Mood disorder & $2.36(1.90-2.94)$ & $<0.001$ & $1.59(1.38-1.84)$ & $<0.001$ & $0.94(0.70-1.26)$ & 0.67 \\
\hline Mood disorder ${ }^{a}$ & $2.44(1.92-3.10)$ & $<0.001$ & $1.48(1.26-1.74)$ & $<0.001$ & $0.84(0.61-1.15)$ & 0.27 \\
\hline Any kind of internalizing disorders & $2.23(1.84-2.70)$ & $<0.001$ & $1.74(1.53-1.98)$ & $<0.001$ & $1.03(0.79-1.34)$ & 0.82 \\
\hline Any kind of internalizing disorders ${ }^{a}$ & $2.26(1.83-2.78)$ & $<0.001$ & $1.64(1.42-1.89)$ & $<0.001$ & $0.94(0.71-1.25)$ & 0.69 \\
\hline \multicolumn{7}{|l|}{ Internalizing disorders 12-month } \\
\hline Bipolar disorder & $3.36(2.00-5.63)$ & $<0.001$ & $0.85(0.54-1.34)$ & 0.48 & $1.08(0.52-2.24)$ & 0.83 \\
\hline Bipolar disorder ${ }^{a}$ & $3.27(1.83-5.82)$ & $<0.001$ & $0.75(0.47-1.21)$ & 0.24 & $0.86(0.40-1.83)$ & 0.70 \\
\hline Depression & $2.65(1.90-3.70)$ & $<0.001$ & $1.59(1.26-2.01)$ & $<0.001$ & $0.86(0.55-1.34)$ & 0.50 \\
\hline Depression $^{a}$ & $2.74(1.91-3.92)$ & $<0.001$ & $1.35(1.04-1.75)$ & 0.02 & $0.72(0.45-1.17)$ & 0.19 \\
\hline Generalized anxiety disorder & $2.31(1.56-3.42)$ & $<0.001$ & $1.46(1.10-1.95)$ & 0.10 & $1.16(0.73-1.86)$ & 0.53 \\
\hline Generalized anxiety disorder ${ }^{a}$ & $2.12(1.37-3.28)$ & 0.001 & $1.19(0.88-1.61)$ & 0.25 & $1.07(0.64-1.80)$ & 0.80 \\
\hline Hypomania & $5.31(2.79-10.10)$ & $<0.001$ & $0.88(0.49-1.57)$ & 0.67 & $0.64(0.27-1.53)$ & 0.32 \\
\hline Hypomania $^{a}$ & $6.44(3.30-12.56)$ & $<0.001$ & $0.90(0.49-1.66)$ & 0.75 & $0.43(0.18-1.04)$ & 0.06 \\
\hline Mania & $3.39(1.77-6.46)$ & $<0.001$ & $1.20(0.67-2.16)$ & 0.54 & $0.98(0.43-2.25)$ & 0.96 \\
\hline Mania $^{a}$ & $3.31(1.62-6.73)$ & 0.001 & $1.14(0.62-2.09)$ & 0.67 & $0.72(0.31-1.71)$ & 0.46 \\
\hline Mood disorder & $2.90(2.14-3.92)$ & $<0.001$ & $1.51(1.20-1.89)$ & $<0.001$ & $0.83(0.55-1.24)$ & 0.36 \\
\hline Mood disorder ${ }^{a}$ & $2.97(2.13-4.14)$ & $<0.001$ & $1.28(1.00-1.65)$ & 0.05 & $0.69(0.45-1.08)$ & 0.11 \\
\hline Any kind of internalizing disorders & $2.74(2.08-3.61)$ & $<0.001$ & $1.49(1.23-1.82)$ & $<0.001$ & $0.88(0.61-1.27)$ & 0.49 \\
\hline Any kind of internalizing disorders ${ }^{a}$ & $2.69(1.99-3.65)$ & $<0.001$ & $1.26(1.01-1.56)$ & 0.04 & $0.77(0.52-1.16)$ & 0.21 \\
\hline \multicolumn{7}{|l|}{ Externalizing disorders lifetime } \\
\hline Alcohol abuse or dependence & $1.65(1.40-1.95)$ & $<0.001$ & $0.25(0.22-0.29)$ & $<0.001$ & $1.57(1.20-2.06)$ & 0.001 \\
\hline Alcohol abuse or dependence ${ }^{a}$ & $1.74(1.45-2.08)$ & $<0.001$ & $0.26(0.23-0.29)$ & $<0.001$ & $1.41(1.06-1.86)$ & 0.02 \\
\hline
\end{tabular}


Table 8 Multivariate analyses for interactions between interpersonal violence, being female and selected mental disorders (Continued)

\begin{tabular}{|c|c|c|c|c|c|c|}
\hline Drug abuse or dependence & $2.42(1.90-3.08)$ & $<0.001$ & $0.39(0.33-0.47)$ & $<0.001$ & $1.24(0.87-1.77)$ & 0.24 \\
\hline Drug abuse or dependence ${ }^{a}$ & $2.46(1.92-3.16)$ & $<0.001$ & $0.37(0.30-0.45)$ & $<0.001$ & $1.07(0.73-.156)$ & 0.74 \\
\hline Any kind of externalizing disorders & $1.89(1.58-2.25)$ & $<0.001$ & $0.28(0.25-0.31)$ & $<0.001$ & $1.36(1.04-1.76)$ & 0.02 \\
\hline Any kind of externalizing disorders ${ }^{a}$ & $2.03(1.68-2.44)$ & $<0.001$ & $0.27(0.24-0.31)$ & $<0.001$ & $1.19(0.90-1.57)$ & 0.23 \\
\hline \multicolumn{7}{|l|}{ Externalizing disorders 12 -month } \\
\hline Alcohol abuse or dependence & $1.56(1.08-2.25)$ & 0.02 & $0.29(0.22-0.38)$ & $<0.001$ & $1.52(0.87-2.65)$ & 0.14 \\
\hline Alcohol abuse or dependence ${ }^{a}$ & $1.67(1.12-2.49)$ & 0.01 & $0.32(0.24-0.42)$ & $<0.001$ & $1.34(0.74-2.44)$ & 0.34 \\
\hline Drug abuse or dependence & $2.22(1.50-3.30)$ & $<0.001$ & $0.33(0.22-0.49)$ & $<0.001$ & $1.20(0.62-2.33)$ & 0.59 \\
\hline Drug abuse or dependence ${ }^{a}$ & $2.41(1.55-3.75)$ & $<0.001$ & $0.29(0.19-0.44)$ & $<0.001$ & $1.06(0.53-2.14)$ & 0.86 \\
\hline Any kind of internalizing disorders & $1.79(1.33-2.40)$ & $<0.001$ & $0.31(0.24-0.39)$ & $<0.001$ & $1.30(0.81-2.08)$ & 2.07 \\
\hline Any kind of internalizing disorders ${ }^{\mathrm{a}}$ & $1.94(1.38-2.71)$ & $<0.001$ & $0.31(0.24-0.40)$ & $<0.001$ & $1.18(0.71-1.96)$ & 0.53 \\
\hline
\end{tabular}

adjusted for age, marital status, income, education, place of residence, immigrant

Table 9 Multivariate analysis for interactions between any abuse, being female and selected mental disorders

\begin{tabular}{|c|c|c|c|c|c|c|}
\hline \multirow[t]{2}{*}{ Selected mental disorders } & \multicolumn{2}{|l|}{ Any kind of abuse } & \multicolumn{2}{|l|}{ Female gender } & \multicolumn{2}{|l|}{ Interactions } \\
\hline & OR $(95 \% \mathrm{Cl})$ & $P$-value & OR $(95 \% \mathrm{Cl})$ & $P$-value & OR $(95 \% \mathrm{Cl})$ & $P$-value \\
\hline \multicolumn{7}{|l|}{ Internalizing problems lifetime } \\
\hline Bipolar disorder & $2.57(1.79-3.70)$ & $<0.001$ & $0.93(0.60-1.42)$ & 0.71 & $1.11(0.65-1.90)$ & 0.71 \\
\hline Bipolar disorder ${ }^{\mathrm{a}}$ & $3.53(2.30-5.41)$ & $<0.001$ & $0.85(0.50-1.46)$ & 0.56 & $0.91(0.49-1.68)$ & 0.76 \\
\hline Depression & $2.40(1.97-2.93)$ & $<0.001$ & $1.68(1.36-2.06)$ & $<0.001$ & $1.22(0.94-1.58)$ & 0.14 \\
\hline Depression $^{a}$ & $2.64(2.12-3.29)$ & $<0.001$ & $1.62(1.27-2.05)$ & $<0.001$ & $1.07(0.80-1.43)$ & 0.64 \\
\hline Generalized anxiety disorder & $2.56(2.07-3.18)$ & $<0.001$ & $1.99(1.57-2.53)$ & $<0.001$ & $1.11(0.84-1.49)$ & 0.46 \\
\hline Generalized anxiety disorder $^{a}$ & $2.48(1.96-3.13)$ & $<0.001$ & $1.83(1.40-2.39)$ & $<0.001$ & $1.04(0.77-1.41)$ & 0.79 \\
\hline Hypomania & $1.98(1.30-3.03)$ & 0.002 & $0.82(0.50-1.33)$ & 0.42 & $1.33(0.71-2.48)$ & 0.37 \\
\hline Hypomania $^{a}$ & $2.69(1.66-4.34)$ & $<0.001$ & $0.75(0.41-1.38)$ & 0.35 & $1.08(0.54-2.17)$ & 0.83 \\
\hline Mania & $2.52(1.75-3.62)$ & $<0.001$ & $0.92(0.60-1.40)$ & 0.69 & $1.12(0.65-1.93)$ & 0.67 \\
\hline Mania $^{a}$ & $3.49(2.27-5.37)$ & $<0.001$ & $0.85(0.50-1.45)$ & 0.55 & $0.91(0.49-1.70)$ & 0.76 \\
\hline Mood disorder & $2.51(2.09-3.02)$ & $<0.001$ & $1.56(1.28-1.89)$ & $<0.001$ & $1.16(0.91-1.48)$ & 0.23 \\
\hline Mood disorder ${ }^{a}$ & $2.88(2.35-3.54)$ & $<0.001$ & $1.55(1.24-1.94)$ & $<0.001$ & $0.99(0.75-1.30)$ & 0.92 \\
\hline Internalizing problems & $2.38(2.03-2.79)$ & $<0.001$ & $1.70(1.43-2.02)$ & $<0.001$ & $1.21(0.97-1.51)$ & 0.09 \\
\hline Internalizing problems ${ }^{\mathrm{a}}$ & $2.58(2.16-3.09)$ & $<0.001$ & $1.70(1.39-2.06)$ & $<0.001$ & $1.05(0.82-1.35)$ & 0.68 \\
\hline \multicolumn{7}{|l|}{ Internalizing problems 12 -month } \\
\hline Bipolar disorder & $3.06(1.80-5.20)$ & $<0.001$ & $0.97(0.50-1.86)$ & 0.92 & $1.01(0.45-2.22)$ & 0.99 \\
\hline Bipolar disorder $^{a}$ & $4.68(2.49-8.81)$ & $<0.001$ & $0.95(0.40-2.23)$ & 0.90 & $0.77(0.30-1.96)$ & 0.58 \\
\hline Depression & $2.72(1.99-3.71)$ & $<0.001$ & $1.81(1.32-2.48)$ & $<0.001$ & $0.95(0.64-1.40)$ & 0.78 \\
\hline Depression $^{\mathrm{a}}$ & $3.18(2.26-4.48)$ & $<0.001$ & $1.40(0.95-2.07)$ & 0.09 & $0.92(0.59-1.43)$ & 0.71 \\
\hline Generalized anxiety disorder & $2.30(1.56-3.38)$ & $<0.001$ & $1.49(0.98-2.27)$ & 0.06 & $1.27(0.77-2.07)$ & 0.35 \\
\hline Generalized anxiety disorder ${ }^{a}$ & $2.46(1.57-3.83)$ & $<0.001$ & $1.15(0.71-1.86)$ & 0.57 & $1.18(0.68-2.05)$ & 0.55 \\
\hline Hypomania & $2.84(1.46-5.51)$ & 0.002 & $0.93(0.43-2.00)$ & 0.85 & $0.80(0.32-2.01)$ & 0.63 \\
\hline Hypomania $^{a}$ & $5.59(2.80-11.17)$ & $<0.001$ & $1.24(0.48-3.20)$ & 0.66 & $0.46(0.17-1.29)$ & 0.14 \\
\hline Mania & $3.73(1.84-7.58)$ & $<0.001$ & $1.63(0.69-3.83)$ & 0.27 & $0.74(0.27-2.07)$ & 0.57 \\
\hline Mania $^{a}$ & $8.61(3.99-18.60)$ & $<0.001$ & $2.70(0.98-7.46)$ & 0.06 & $0.33(0.11-1.01)$ & 0.05 \\
\hline Mood disorder & $2.85(2.13-3.82)$ & $<0.001$ & $1.70(1.26-2.31)$ & 0.001 & $0.91(0.63-1.32)$ & 0.63 \\
\hline Mood disorder $^{\mathrm{a}}$ & $3.58(2.60-4.94)$ & $<0.001$ & $1.45(0.99-2.12)$ & 0.06 & $0.81(0.53-1.24)$ & 0.34 \\
\hline
\end{tabular}


Table 9 Multivariate analysis for interactions between any abuse, being female and selected mental disorders (Continued)

\begin{tabular}{|c|c|c|c|c|c|c|}
\hline Internalizing problems & $2.49(1.95-3.20)$ & $<0.001$ & $1.57(1.20-2.04)$ & 0.001 & $1.04(0.76-1.44)$ & 0.79 \\
\hline Internalizing problems ${ }^{a}$ & $3.03(2.30-4.00)$ & $<0.001$ & $1.31(0.96-1.80)$ & 0.09 & $0.94(0.65-1.34)$ & 0.72 \\
\hline \multicolumn{7}{|l|}{ Externalizing problems lifetime } \\
\hline Alcohol abuse or dependence & $2.57(2.25-2.94)$ & $<0.001$ & $0.28(0.24-0.33)$ & $<0.001$ & $1.16(0.92-1.45)$ & 0.20 \\
\hline Alcohol abuse or dependence ${ }^{a}$ & $2.47(2.12-2.89)$ & $<0.001$ & $0.27(0.22-0.33)$ & $<0.001$ & $1.12(0.87-1.43)$ & 0.37 \\
\hline Drug abuse or dependence & $3.15(2.61-3.80)$ & $<0.001$ & $0.43(0.35-0.54)$ & $<0.001$ & $1.13(0.85-1.50)$ & 0.41 \\
\hline Drug abuse or dependence ${ }^{a}$ & $3.45(2.78-4.28)$ & $<0.001$ & $0.38(0.29-0.50)$ & $<0.001$ & $1.06(0.75-1.48)$ & 0.74 \\
\hline Externalizing disorders & $2.74(2.41-3.12)$ & $<0.001$ & $0.31(0.27-0.36)$ & $<0.001$ & $1.09(0.89-1.34)$ & 0.42 \\
\hline Externalizing disorders ${ }^{a}$ & $2.08(2.42-3.26)$ & $<0.001$ & $0.29(0.24-0.34)$ & $<0.001$ & $1.02(0.81-1.28)$ & 0.87 \\
\hline \multicolumn{7}{|l|}{ Externalizing disorders 12 -month } \\
\hline Alcohol abuse or dependence & $1.47(1.09-1.97)$ & 0.01 & $0.29(0.20-0.40)$ & $<0.001$ & $1.52(0.98-2.38)$ & 0.06 \\
\hline Alcohol abuse or dependence ${ }^{a}$ & $1.87(1.29-2.70)$ & 0.001 & $0.28(0.18-0.72)$ & $<0.001$ & $1.51(0.89-2.58)$ & 0.13 \\
\hline Drug abuse or dependence & $1.93(1.37-2.72)$ & $<0.001$ & $0.45(0.28-0.71)$ & 0.001 & $0.96(0.53-1.74)$ & 0.88 \\
\hline Drug abuse or dependence ${ }^{a}$ & $3.00(1.99-4.53)$ & $<0.001$ & $0.27(0.15-0.48)$ & $<0.001$ & $1.22(0.61-2.42)$ & 0.57 \\
\hline Externalizing disorders & $1.61(1.25-2.06)$ & $<0.001$ & $0.35(0.26-0.47)$ & $<0.001$ & $1.18(0.81-1.73)$ & 0.39 \\
\hline Externalizing disorders ${ }^{a}$ & $2.14(1.56-2.94)$ & $<0.001$ & $0.29(0.20-0.41)$ & $<0.001$ & $1.30(0.82-2.07)$ & 0.27 \\
\hline
\end{tabular}

adjusted for age, marital status, income, education, place of residence, immigrant

\section{Acknowledgements}

The analysis presented in this paper was conducted at the Saskatchewan Research Data Centre (SKY-RDC), which is part of the Canadian Research Data Centre Network (CRDCN). The views expressed in this paper do not necessarily represent the CRDCN's or that of its partners.

\section{Funding}

The project was facilitated by funding from a Molstad Intramural Research Award from Department of Psychiatry, University of Saskatchewan, Canada, and a start-up fund from Douglas Mental Health University Institute, Montreal, Canada.

\section{Availability of data and material}

This study uses a dataset from Statistics Canada. Permission was granted for analyzing a master file of Canadian Community Health Survey 2012: Mental Health from Statistics Canada. The data is available to bonda fide researcher in university research data centres affiliated the Canadian Research Data Centre Network (CRDCN).

\section{Authors' contributions}

XM and CD conceived and designed the study. XM completed the analysis and first draft of this manuscript. XM and CD reviewed and amended the draft and agreed the final version of manuscript.

\section{Competing interests}

The authors' declare that they have no competing interests.

\section{Consent for publication}

Not applicable.

\section{Ethics approval and consent to participate}

This is secondary analysis of existing dataset. The survey was approved by the Statistics Canada ethics review committee. Respondents were informed and gave written consent to being surveyed.

\section{Author details}

'Department of Psychiatry, McGill University and Douglas Mental Health University Institute, 6875 boul. LaSalle, Verdun, Montreal, QC, Canada. ${ }^{2}$ Department of Psychiatry \& School of Public Health, University of Saskatchewan, Saskatoon, SK, Canada.
Received: 19 February 2016 Accepted: 13 October 2016

Published online: 15 November 2016

\section{References}

1. Hussey JM, Chang JJ, Kotch JB. Child maltreatment in the United States: prevalence, risk factors, and adolescent health consequences. Pediatrics. 2006;118(3):933-42.

2. Butchatt A, Harvey A, Mian M, Furniss T. Preventing child maltreatment: a guide to taking action and generating evidence. World Health Organization and International Society for Prevention of Child Abuse and Neglect. 2006. http://apps.who.int/iris/bitstream/10665/43499/1/9241594365_eng.pdf . Accessed 30 Jan 2016.

3. Gilbert R, Widom CS, Browne K, Fergusson D, Webb E, Janson S. Burden and consequences of child maltreatment in high-income countries. Lancet. 2009:373(9657):68-81.

4. Gilbert R, Fluke J, O'Donnell M, Gonzalez-Izquierdo A, Brownell M, Gulliver P, et al. Child maltreatment: variation in trends and policies in six developed countrie. Lancet. 2012;379(9817):758-72.

5. Walsh WA, Dawson J, Mattingly MJ. How are we measuring resilience following childhood maltreatment? Is the research adequate and consistent? What is the impact on research, practice, and policy? Trauma Violence Abuse. 2010;11(1):27-41.

6. Williamson JM, Borduin CM, Howe BA. The ecology of adolescent maltreatment: a multilevel examination of adolescent physical abuse, sexual abuse, and neglect. J Consult Clin Psychol. 1991;59(3):449-57.

7. Howe ML, Cicchetti D, Toth SL. Children's basic memory processes, stress, and maltreatment. Dev Psychopathol. 2006;18(3):759-69.

8. Thompson MP, Kingree JB, Desai S. Gender differences in long-term health consequences of physical abuse of children: data from a nationally representative survey. Am J Public Health. 2004:94(4):599-604.

9. Afifi TO, Macmillan HL, Boyle M, Taillieu T, Cheung K, Sareen J. Child abuse and mental disorders in Canada. CMAJ. 2014;186(9):E324-32.

10. Krugman SD, Lane WG, Walsh CM. Update on child abuse prevention. Curr Opin Pediatr. 2007;19(6):711-8.

11. Wekerle $\mathrm{C}$. The dollars and senselessness in failing to prioritize childhood maltreatment prevention. Child Abuse Negl. 2011;35(3):159-61.

12. Anda RF, Felitti VJ, Bremner JD, Walker JD, Whitfield C, Perry BD, et al. The enduring effects of abuse and related adverse experiences in childhood. A convergence of evidence from neurobiology and epidemiology. Eur Arch Psychiatry Clin Neurosci. 2006;256(3):174-86.

13. Catuzzi JE, Beck KD. Anxiety vulnerability in women: a two-hit hypothesis. Exp Neurol. 2014;259:75-80. 
14. Moreno-Peral P, Conejo-Ceron S, Motrico E, Rodríguez-Morejón A, Fernández A, García-Campayo J, Roca M, et al. Risk factors for the onset of panic and generalised anxiety disorders in the general adult population: a systematic review of cohort studies. J Affect Disord. 2014;168:337-48.

15. Bobzean SA, DeNobrega AK, Perrotti LI. Sex differences in the neurobiology of drug addiction. Exp Neurol. 2014;259:64-74.

16. Rescorla L, Achenbach TM, Ivanova MY, Dumenci L, Almqvist F, Bilenberg N, et al. Epidemiological comparisons of problems and positive qualities reported by adolescents in 24 countries. J Consult Clin Psychol. 2007;75(2):351-8.

17. Zahn-Waxler C, Shirtcliff EA, Marceau K. Disorders of childhood and adolescence: gender and psychopathology. Annu Rev Clin Psychol. 2008;4:275-303.

18. Seedat S, Scott KM, Angermeyer MC, Berglund P, Bromet EJ, Brugha TS, et al. Cross-national associations between gender and mental disorders in the World Health Organization World Mental Health Surveys. Arch Gen Psychiatry. 2009;66(7):785-95.

19. Steel Z, Marnane C, Iranpour C, Chey T, Jackson JW, Patel V, et al. The global prevalence of common mental disorders: a systematic review and meta-analysis 1980-2013. Int J Epidemiol. 2014;43(2):476-93.

20. Fletcher JM. Childhood maltreatment and adolescent and young adult depression. Soc Sci Med. 2009;68(5):799-806.

21. Arnow BA, Blasey CM, Hunkeler EM, Lee J, Hayward C. Does gender moderate the relationship between childhood maltreatment and adult depression? Child Maltreat. 2011;16(3):175-83.

22. Kristman-Valente A, Wells EA. The role of gender in the association between child maltreatment and substance use behavior: a systematic review of longitudinal research from 1995 to 2011. Subst Use Misuse. 2013;48(8):645-60.

23. Walsh CA, MacMillan HL, Trocme N, Jamieson E, Boyle MH. Measurement of victimization in adolescence: development and validation of the Childhood Experiences of Violence Questionnaire. Child Abuse Negl. 2008;32(11): 1037-57.

24. Binder EB, Bradley RG, Liu W, Epstein MP, Deveau TC, Mercer KB, et al. Association of FKBP5 polymorphisms and childhood abuse with risk of posttraumatic stress disorder symptoms in adults. JAMA. 2008;299(11):1291-305.

25. Widom CS, DuMont K, Czaja SJ. A prospective investigation of major depressive disorder and comorbidity in abused and neglected children grown up. Arch Gen Psychiatry. 2007;64(1):49-56.

26. Langeland W, Draijer N, van den Brink W. Psychiatric comorbidity in treatmentseeking alcoholics: the role of childhood trauma and perceived parental dysfunction. Alcohol Clin Exp Res. 2004;28(3):441-7.

27. Douglas KR, Chan G, Gelernter J, Arias AJ, Anton RF, Weiss RD, et al. Adverse childhood events as risk factors for substance dependence: partial mediation by mood and anxiety disorders. Addict Behav. 2010;35(1):7-13.

28. Briere J, Elliott DM. Prevalence and psychological sequelae of self-reported childhood physical and sexual abuse in a general population sample of men and women. Child Abuse Negl. 2003;27(10):1205-22.

29. Conroy E, Degenhardt L, Mattick RP, Nelson EC. Child maltreatment as a risk factor for opioid dependence: Comparison of family characteristics and type and severity of child maltreatment with a matched control group. Child Abuse Negl. 2009;33(6):343-52.

30. Dube SR, Anda RF, Whitfield CL, Brown DW, Felitti VJ, Dong M, et al. Longterm consequences of childhood sexual abuse by gender of victim. Am J Prev Med. 2005;28(5):430-8.

31. Schlack R, Petermann F. Prevalence and gender patterns of mental health problems in German youth with experience of violence: the KiGGS study. BMC Public Health. 2013;13:628.

32. Boyd A, Van de Velde S, Vilagut G, de Graaf R, O'Neill S, Florescu S, et al. Gender differences in mental disorders and suicidality in Europe: Results from a large cross-sectional population-based study. J Affect Disord. 2015;173:245-54.

33. Forlani C, Morri M, Ferrari B, Dalmonte $\mathrm{E}$, Menchetti $\mathrm{M}$, De Ronchi $\mathrm{D}$, et al. Prevalence and gender differences in late-life depression: a populationbased study. Am J Geriatr Psychiatry. 2014;22(4):370-80.

34. Rich JL, Byrne JM, Curryer C, Byles JE, Loxton D. Prevalence and correlates of depression among Australian women: a systematic literature review, January 1999- January 2010. BMC Res Notes. 2013;6:424.

35. Widom CS, White HR, Czaja SJ, Marmorstein NR. Long-term effects of child abuse and neglect on alcohol use and excessive drinking in middle adulthood. J Stud Alcohol Drugs. 2007;68(3):317-26.

36. Jasinski JL, Williams LM, Siegel J. Childhood physical and sexual abuse as risk factors for heavy drinking among African-American women: a prospective study. Child Abuse Negl. 2000;24(8):1061-71.
37. Langeland W, Hartgers C. Child sexual and physical abuse and alcoholism: a review. J Stud Alcohol. 1998:59(3):336-48.

38. Maniglio R. The impact of child sexual abuse on health: a systematic review of reviews. Clin Psychol Rev. 2009;29(7):647-57.

39. Nickel MK, Tritt K, Mitterlehner FO, et al. Sexual abuse in childhood and youth as psychopathologically relevant life occurrence: cross-sectional survey. Croat Med J. 2004;45(4):483-9.

40. Griffing S, Lewis CS, Jospitre T, Chu M, Sage R, Primm BJ, et al. The process of coping with domestic violence in adult survivors of childhood sexual abuse. J Child Sex Abus. 2006;15(2):23-41.

41. Roberts R, O'Connor T, Dunn J, Golding J, ALSPAC Study Team. The effects of child sexual abuse in later family life; mental health, parenting and adjustment of offspring. Child Abuse Negl. 2004;28(5):525-45.

\section{Submit your next manuscript to BioMed Central and we will help you at every step:}

- We accept pre-submission inquiries

- Our selector tool helps you to find the most relevant journal

- We provide round the clock customer support

- Convenient online submission

- Thorough peer review

- Inclusion in PubMed and all major indexing services

- Maximum visibility for your research

Submit your manuscript at www.biomedcentral.com/submit
) Biomed Central 